In Books that Changed the World Mr. Downs said: "In view of the extreme diffculty as to readability of perhaps a majority of titles on the select list, this question may reasonably be asked: How could these works exert influence on any except a narrow band of specialists? ... Their influence, accordingly, has resulted from interpretation by experts." I would ask another question: in view of the extreme difficulty of understanding many of the books that have molded our modern consciousness, and the equally extreme difficulty of finding time to read them, isn't it better to read Mr. Downs's lucid summaries than to fail to read most of the originals?-Katharine M. Stokes, Western Michigan University, Kalamazoo.

\section{A Regional Survey}

College, University and Special Libraries of the Pacific Northwest. Edited by Morton Kroll. (Pacific Northwest Library Association Development Project Reports, Volume III). Seattle, University of Washington Press, 1961. x, 310p. $\$ 6.75$.

This study, volume three of the reports of the Pacific Northwest Library Association Development Project, consists of two parts. Its first third covers college and university libraries, while the remaining two-thirds presents surveys of three types of special libraries: legal, medical and federal. In both cases the geographical coverage is the four states of Washington, Oregon, Idaho, and Montana and the province of British Columbia. Only three of the six chapters ("Policy Making and Control in College and University Libraries," "The Academic Library and the Community: A Study of Relationships between Public and Academic Libraries in the Pacific Northwest," and "The Federal Library in the Pacific Northwest") have individual authors; teams of two ("The Research Function of College and University Libraries in the Pacific Northwest"), four ("The Law Libraries of the Pacific Northwest"), and six ("The Medical Libraries of the Pacific Northwest") prepared the other three chapters.

The first of the three chapters on college and university libraries provides an excellent view of the structure of policy making. The author first considers policy making within the library and then examines relations with nonlibrary groups. The writer, a political scientist, concludes that the most effective forms and procedures of administration are those which keep open the channels of communications. He also emphasizes that procedures are no better than the men who use them-certainly a plea for more competent and qualified administrators. Students of library management, take heed!

The next chapter explores the library's role in research. Although a discussion of resources devotes one paragraph to listing some special strengths of the area's libraries, the writers point out that "highly reliable knowledge of the actual state of the collections in the various fields throughout the region must await more exact and extensive surveys." Not mentioned is the fact that a new edition of John Van Male's Resources of Pacific Northwest Libraries (1943) could accomplish this. The claim of the authors to concentrate "on four selected fields: physical sciences, social sciences, biological sciences, and humanities" puzzles this reviewer, since most scholars would think of these areas as embracing all of the disciplines within the liberal arts and sciences, excluding only the various professional fields of law, medicine, architecture, etc. After brief consideration of finance, services, and facilities the chapter concludes with twelve "tentative recommendations" ranging from more efforts to develop collections and to fill gaps to an "improved system for controlling the time of binding journals."

Perhaps the most striking thought left with the reader of Carlson's study of the academic library and the community is not the lack of examples of a combined publiccollege library service but the lack of interest in experimenting with it. He offers the explanation that, in spite of "a great deal of effective though informal cooperation" between the two types, "the definite feeling persists that each . . . has its own clientele."

The reader of the chapters which form part one needs to bear in mind that each has a somewhat different scope. The first does not indicate how many libraries it covers, but the examples tend to draw on the larger academic libraries. Chapter 2 is based primarily on nine institutions (the universities 
of British Columbia, Washington, Oregon, Idaho, and Montana and the Washington, Oregon, Idaho, and Montana state colleges). For chapter 3 the author draws on replies to letters of inquiry and visits to Portland, Seattle, and Vancouver. $\mathrm{He}$ also presents statistics giving volumes and enrollment or population for 87 public and academic libraries. One would like to have seen further data of this nature on finance, personnel, building, and services incorporated into chapter 2; without it, the reader finds it difficult adequately to assess the "tentative recommendations" proposed.

In the survey of law libraries there are sections dealing with conditions in each of the four states and in the province. The nature and extent of resources and their availability to the practicing lawyer receive most attention. The authors point out that the statutes, reports, digest, and citators of a lawyer's own and of the federal or dominion jurisdictions, which are adequate for matters subject to statutory regulation or for matters litigated earlier in the jurisdiction, prove deficient for cases involving other states or for cases of first impression. This is especially true in rural areas; a three-way program of improvement at the state level is suggested: a central lending library, a union list of recommended legal treatises and a traveling librarian "to organize, weed, set up subscription and purchasing systems .... to organize methods of circulation control and to train clerical assistants."

The longest chapter in the book and that which presents the most detailed information covers medical libraries. Parallel to the treatment of law libraries, there are sections analyzing the present situation in the region's four states and province. Thirty-three tables following the text present a wealth of background data on collections, budgets, sources of funds, staff salaries and benefits, buildings and equipment, and services. These data not only give many basic facts in detail but provide supporting evidence for the general conclusion that medical libraries and library service, like their legal counterparts, are inadequate. The suggested solution differs in being one of approach on the regional rather than the state basis-perhaps because the universality of the health sciences contrasts with the special nature of each legal jurisdiction.

The author of the final chapter, on the federal library, first outlines the national library systems of several United States government departments (e.g., Air Force, Veterans Administration) and then draws a general picture of the federal librarian, the mission and status of the library, its patrons, its collections, and its relations with other libraries. The Canadian federal library receives briefer treatment.

The book is well-printed by photo-offset, with notes appearing at the end. Several small improvements might be suggested: all tables might have been numbered consecutively and listed after the table of contents to avoid the necessity of flipping pages when trying to locate a table for the second time; moreover, the thirty-three tables supplementing the chapter on medical libraries appear on pages 245-70, none of which carries a page number! In the index, all subjects covered in the last chapter have apparently blind references, unless one realizes that he should add 26 to the page given (e.g., 259 becomes 285). Probably it was not originally intended to publish the 33 tables on medical libraries; when they were inserted between chapters 5 and 6 no changes were made in page references to chapter 6 .

After the reader has finished this interesting survey, several questions are likely to remain with him. What is to be the future role of the Pacific Northwest Bibliographic Center? It receives only passing mention in the text, figures in three recommendations. and has four entries in the index. What about other special libraries in the region? In spite of the title of the survey it covers only three groups of special libraries.

Although one can agree with the editor's statement that "the enormous diversity of medical and law libraries, and the variation in research collections presented a greater problem than any one individual could cover in the relatively brief period of time available to the project to accomplish its work," nevertheless it seems to this reader that each of the six chapters stands more as an individual study than as part of an integrated whole. An over-all concluding and synthesizing chapter might have, at least partially, avoided this impression.

The volume contains twenty-five specific recommendations (twelve for college and university libraries, six for medical and seven for federal). In the long run the report's importance will probably depend on 
how much it stimulates librarians to accept and to act on these recommendations.William Vernon Jackson, Graduate School of Library Science, University of Illinois.

\section{Shelf Classification}

American Library Classification, with Special Reference to the Library of Congress. By Leo E. LaMontagne. Hamden, Conn.: Shoe String Press, 1961. 443p. \$9.50.

This volume by Leo LaMontagne is as much biographical as it is historical. After an introductory section on Thomas Jefferson and the Library of Congress, a chapter is concerned with the work of Socrates, Plato, Callimachus, Thabanus Maurus, Avicenna, and others of the early period. LaMontagne notes the various ways in the approach to knowledge-the similarities and differences. "I have taken all knowledge to be my province," Bacon wrote to Lord Burghley in 1592 (p. 82). Knowledge has gone a long way since Bacon divided it into two parts: human knowledge (from the sense), and theology (from revelation). This section is interesting but adds little to the direct development of the basic theme, a discussion of the Library of Congress classification.

Duncan Campbell, a Boston bookseller, issued the first book classification in the United States-a sales catalog published in 1693 - according to LaMontagne. The catalog dealt with the library of Samuel Lee, and the books were listed by language, size, and subject. The first classification used in American libraries was the arrangement of reliious topics contained in Bibliotheca Parochialis of the Reverend Thomas Bray, issued in London in 1697. Bray's classification of religion contained ten main divisions and many subdivisions. The 1723 Harvard College arrangement (developed by Joshua Gee), the 1703 (?) classification of William Proctor for the William Byrd Collection, the 1731 essay of Samuel Johnson (of Guilford, Connecticut) on the classification of knowledge, and the 1743 classified catalog of Thomas Clap at Yale College are described by LaMontagne. In summary of these early arrangements, the author writes: "The classi- fications thus far described reveal that American library classification, like the culture of which it forms a part, was both derivative and original."

How classification grew from simple to complex arrangements is shown in the development of the scheme (1764) for The Redwood Library, in Newport, Rhode Island, prepared by the Reverend Ezra Stiles, who later became president of Yale College. This arrangement was similar to the simple scheme of divisions in the catalog of Samuel Lee's library. Further steps in the road to complexity include the classified catalog of the Library Company of Philadelphia (1789), supposed to have been compiled by Zechariah Poulson, Jr.; the classification of T. M. Harris at Harvard College (1793); the 1816 classifications of A. E. B. Woodward (who developed the so-called "Catholepistemia") and of Jeremy Bentham (who developed his Chrestomathia). LaMontagne states that Woodward's system, destined for oblivion, contained much in the development of laws of classification-such "laws" as comprehensiveness, logical division, correlation of subjects, approach from the simple to the complex, clear definition of coverage by subjects, clear definition of relationship between subjects, appropriate terminology, and the absence of excessive subdivision. The 1821 Harvard College classification, the 1824 clasification of the American Philosophical Society, the system of the Charleston Society Library (1826), the introduction of the Brunet system at Harvard in 1830 , and the classifications used at the Library Company of Philadelphia, the New York Society Library, Cambridge (Massachusetts) High School, and the U.S. Military Academy at West Point are reviewed, as well as the contributions of Roswell Park, S. Hastings Grant, and Romain Merlin.

The major contribution of this work is the discussion of the development of the $\mathrm{Li}$ brary of Congress classification (chapters XIII-XVIII). The immediate usefulness of this volume, so long as there is not available a detailed guide to the Library of Congress classification, will be primarily the description of the various schedules. The development and suggestions for the future of this system are considered. However, there is limited analysis of the pecularities of the separate classes. There appears still to be a need for a thorough and detailed manual on 